\title{
Civil Justice Reform and MANDATORy Civil MEDIATION IN SASKATCHEWAN: Lessons from a Maturing Program
}

\author{
DR. Julie MaCfarlaniः AND MICHAEla KEFT"*
}

This article examines the development of the civil court-connected mediation program in Saskatchewan. The program was evaluated by the authors following its first 10 years of operation. using focus groups and imterve w's with lawyers, clients, medialors and judges across the province. The resulting data shows a broad level of satisfaction with the mediation program among clients and a growing acceptance by the Bar and the Bench. There is an interesting alignment of views between some lanyers and clients describing a desire for proactive (albeit non-evaluative) mediators. The authors go on to discuss possible program enhancements to promote greater fexibility in case referral type, timing and management and to further extend acceptance of the program. The authors conclude that the Saskatchewan program provides a good example of a "maturing" courl-connected mediation program, demonstrating the importance of changes in allitudes and behaviours especially among lawyers if justice reform in the form of courtconnecsed mediation is so have a lasting impact on the adversarial cullure of the courts.
Cet article examine la mise sur pied du programme de médiation civile rattaché d̀ la cour de la Saskaichewan. Le programme a fait l'objet d'une ivaluation de la part des auteurs une decennie après son adoption. Celle dernière a èj effectuée au mojen de groupes de discussion et d'entrevies avec des avocats. des clients. des médiateurs et des juges des quatre coins de la province. Les résultats recueillis révèlent que les clients sont très satisfaits avec le programme de médiation el que son degré d'acceptation est à la hautsse cuuprìs du Barreau et de la Cour. Les opinions de cursains avocats et clients semblent s'aligner. revelam le desir d'avoir des médiateurs proactifs (bien que non discrimimatoire). les auteurs discustent d'améliorations qui pourraient eitre apporties au programme afin d'obtenir une plus grande souplesse au plan du type. du moment choisi et de la gestion de renvoi de cause en vue d'accroitre lacceptation duprogramme. Les auteursterminenten disant que le programme de la Saskatchewan est un bon exemple d' un programme de mediation ratiachéc is la cour "en plein mirissement" ce qui confirme l'importance d'un changement d'atritude et de comportement, surtou parmi les avocats, sil'on veut que la riforme judiciaire. sous forme de médiation rattachice à la cour, ait un impact durable sir la nature accusatoire de la cour.

\section{TABLE OF CONTENTS}

I. INTRODUCTION .......................... 678

II. Evaluating the Saskatchewan Program $\ldots \ldots \ldots \ldots \ldots \ldots 681$

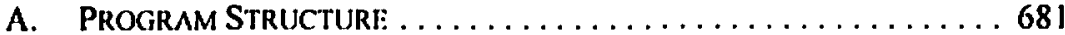

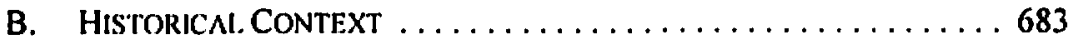

C. EVAI.UATION METHODOLOGY $\ldots \ldots \ldots \ldots \ldots \ldots \ldots \ldots, 685$

III. FEEDBACK From LAWYERS $\ldots \ldots \ldots \ldots \ldots \ldots \ldots \ldots \ldots \ldots \ldots, 688$

A. Changing Views: Acceptance of Mediation .......... 688

B. Being PREPARED: Pre-MEDIATION INFormation

EXCHANGE . . . . . . . . . . . . . . . . . . . . . 689

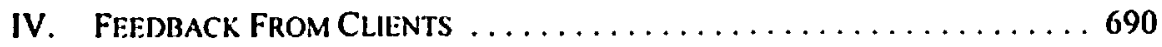

A. Collateral Benefts: The Value of $A$

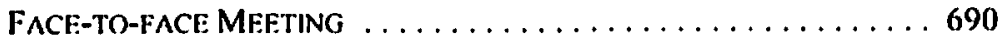




\section{B. THE LAWYER'S ROLE: LAWYERS SHAPING THEIR}

Clients' Experiences . . . . . . . . . . . . . . 691

V. FEEDBACK ABOUT THE MEdatoR's Role:

THE CAll For Pro-activity ................... 693

VI. Characteristics of a Maturing Program . . . . . . . . . . . 697

A. A PREFERENCE For FLEXIBILITY . . . . . . . . . . . . 697

B. Goal AlignMEnt . . . . . . . . . . . . . . . . . . . 699

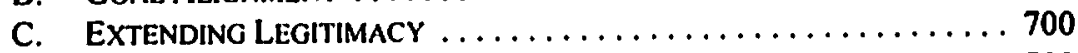

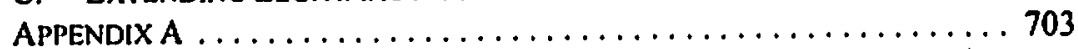

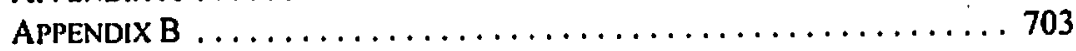

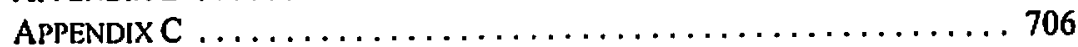

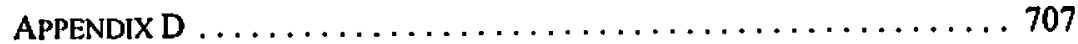

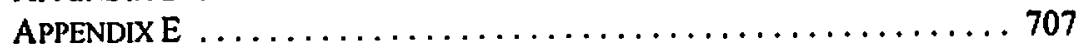

APPENDIX F ....................... 708

\section{INTRODUCTION}

Court-connected mediation is becoming an increasingly familiar process in Canada, a model of dispute resolution that litigants and lawyers encounter regularly in different venues across the country. Ten years ago, only Ontario and Saskatchewan were innovating in this area. While Ontario's Superior Court mandatory mediation program has received widespread attention as it progressed from Practice Directions to an established rule of civil procedure, Saskatchewan's equally ambitious civil justice reform has gone relatively unnoticed. Moreover, the Saskatchewan program is unique in its focus on broadening access to justice and quality outcomes, in a province that has never suffered from the type of court backlog that has driven reforms elsewhere. After ten years of experience, combined with an extensive earlier history of farm debt mediation, the Saskatchewan Queen's Bench program offers an excellent window into an evolved court-connected mediation model — and a chance to look deeper into the incremental development of civil justice reform.

Ten years ago, the Saskatchewan legislation proposing mandatory mediation in the Queen's Bench was met with an outburst of rhetoric on all sides. Program administrators and their political leaders described the proposed mandatory mediation program as a response to problems in the civil justice system. During the second reading of the Bill, Justice Minister Robert Mitchell set the stage with the following statement:

In the best of all possible worlds, justice would be done efficiently, inexpensively and with minimal emotional pain to those involved. But until legal reforms take place ... you're entering a less than perfect world that will require caution, stamina and bravery to survive. ${ }^{2}$ Cases: An Evaluation of the Ontario Couri (General Division) ADR Centre (Toronto: Queen's Printer, 1995) and Robert Hann \& Associates, Evaluation of the Ontarto Mandatory Mediation Program (Rule 24.1) Final Report - The First 23 Months (Toronto: Queen's Printer, 2001).

: Saskatchewan, Legislative Assembly, Hansard (18 March 1994) at 14 (Hon. R.W. Mitchelt), online: Legislative Assembly of Saskalchewan <www.legassembly.sk.ca/hansard/22L4S/940318.pdrP. This quotation - taken from Chief Justice Warren Berger of the United States Supreme Courn - was published in the Financial Post. Its citation was not included in the second reading speech. 
"The challenge," he continued, "is fundamental - the justice system's failure to serve the needs of our citizens." He went on to identify "two major failings" as "the high cost and delay associated with traditional adversarial litigation," and the fact that "the formal adversarial basis of litigation is simply not suited to resolving certain types of disputes," including disputes that carry a "heavy emotional overtone."

The Saskatchewan Bar was less convinced. Lawyers saw the imposition of mediation as removing their control from the litigation and resolution process, and carrying the suggestion that they were failing in their role as advocates. They responded, in defense, that the new program added additional expense and delay to litigation and that "the interests of litigants ... are better served by the advice of counsel than by the compulsory mediation provisions recently introduced." The polarization of the debate surrounding mandatory mediation continued through the program's early years.

The original concerns of the Saskatchewan Bar regarding mandatory civil case mediation were unsurprising and mirrored reservations expressed in other Bars over the introduction of these types of initiative. Court-connected mediation programs are embedded within a process that is inherently adversarial. The interaction of those programs with the litigation process - and the norms, behaviors and expectations that support it - produces a complex and often tense interplay of opposing cultures of conflict and conflict resolution. ${ }^{6}$ Mandatory mediation introduced a process that was new to most lawyers and clients and concepts that challenge traditional expectations of dispute resolution between adversaries. Mediators invite collaborative discussion at a time when most lawyers and their clients are preparing for battle. The process of mediation shifts the focus away from the law to the parties' underlying interests and, in its tone, differs fundamentally from the steps of a lawsuit that come before and after.

The passage of ten years, however, has produced dramatic change in the shape and size of resistance to mandatory mediation, a change noticeable in both the process and the outcome of the Saskatchewan program's recent evaluation. ${ }^{8}$ Representatives of the Government, Bar, Bench and the professional mediation association came together to work in an Advisory Committee, which provided both input and legitimacy to the independent

Ibid. at 14.

Jbid. at 15.

This quote is taken from a resolution introduced at a Saskatchewan Bar Association annual meeting. five months after the mediation program's start-up, calling for the repeal of the legislation; Regina Bar Association, The Mediation Resolution, 1995 (11 May 1995) [unpublished].

" For a discussion of the possible outcomes of merging or blending different cultures of conflict resolution, see Julie Macfarlane "Commentary: When Cultures Collide" in Catherine Bell \& David Kahane, eds., Imerculurat Dispute Resolution in Aboriginal Contexts (Vancouver: University of British Columiba Press, 2004) 94.

- For a description of the impact of procedural difterences on conflict dynamics. see for example Julic Macfarlane, "The Mediation Alternative" in Rethinking Disputes: The Mediation Alternative (Toronto: Emond Montgomery, 1997) I and Carrie Menkel-Meadow, "The Trouble with the Adversary System in a Postmodern, Multicultural World" (1996) 38 Wm. \& Mary L. Rev. 5 at 5.

* Julie Macfarlane \& Michaela Keet, Learning from Experience: An fivaluation of the Saskatchewan Queen's Bench Mediation Program: Final Report (Regina: Saskatchewan Justice. 2003), online: Saskatchewan Justice < wmw.saskjustice.gov.sk.ca/DisputeResolution/pubs/QBCivilEvaluation.pdf> [Learning from Experience]. 
evaluation. Lawyers, judges, clients and mediators committed themselves to conversations in focus groups and in interviews about the pros and cons of their experiences with mandatory mediation. The evaluation concluded that the central issue in this debate is no longer whether there should be some form of mediation requirement in Saskatchewan, but how the program can be enhanced and improved for lawyers and clients alike. The evaluation pinpointed a number of lessons from experience that suggested modifications in the systems design and provided useful signposts for other, less evolved court-connected programs.

Program evaluation in this setting has tended to focus on quantitative, efficiency-related characteristics including settlement rates, impact on court dockets and comparative costs of the processes for clients. ${ }^{9} \mathrm{~A}$ focus on efficiencies reflects the primary objective of most courtbased and institutional mediation programs: saving resources expended on protracted litigation. However the concerns that have tended to drive programs in other parts of Canada have played a secondary role in Saskatchewan. Instead, a concern for the quality of people's encounters with the civil justice system figures prominently in the original objectives for the Saskatchewan program. Mediation here is said to be about broadening the parameters of the dispute, returning control to the parties and paying respect to relationships. The Saskatchewan program envisioned a greater role for litigants in the resolution of their own disputes, an objective that emerged from the Department of Justice's broader Core Strategy on Dispute Resolution:

\footnotetext{
Behind this Core Strategy lies a recognition of a growing expectation by people throughout the world for greater input into the resolution of their own disputes and greater control over solutions that affect them. No longer are people completely satisfied with decisions that are imposed on them by a third party. Pcople are secking solutions that they have created themselves. ${ }^{10}$
}

Quantitative research methods by their very nature cannot capture the details and nuances of such experiences. An evaluation of how successful the Saskatchewan program has been in enriching the experience of participatory justice in the court system called for the adoption of a qualitative approach to data collection and analysis. This is described in further detail below.

The ultimate impact of mandatory mediation in Saskatchewan was expected to be both systemic and cultural, affecting how litigants understand the civil justice process and their role and responsibilities within it, and how lawyer-advocates participate in consensus-based problem-solving processes. Some of the indices of cultural change can be gleaned from

" See Roselle L. Wissler, "Court-Connected Mediation in General Civil Cases: What We Know from Empirical Research" (2002) 17 Ohio St. J. Disp. Resol. 641.

"' Mediation Services, Department of Justice, Saskatchewan.Justice: Core Strategy on Dispule Resolution at $\mathfrak{l}$ [unpublished]. This theme is repeated in the second reading speech presented by the Minister of Justice during the Bill's introduction into the Legislative Assembly. "[mediation] leaves consumers in control of. and participating directly in. the decisions that are made": (supra note 2 at 16). The Mission Statement of Mediation Services describes the importance of offering people the "option and the tools to settle differences will dignity and control in a non-threatening environment" [emphasis added]. reinforced by references throughout the Mission Statement to the branch 's mandate in educating people so that they can use the tools themselves: Mediation Services, Department of Justice, "Mission Statement" at I [unpublished]. 
earlier studies." They include how seriously lawyers prepare for mediation; how and how much information is exchanged in advance of mediation; the seniority and experience of the lawyer sent to represent a client in mediation; expanding expectations of client participation in negotiation discussions; the willingness of counsel to accept a range of mediator expertise including non-lawyer mediators; the parallel use made of private voluntary mediation; and generally, the recognition of the need for new and different skills and knowledge in order to maximize the effectiveness of mediation. Indices that appear to reflect growing maturity among clients with the mediation process include recognition of the range of uses and benefits (including but not limited to settlement) of an carly face-to-face meeting with the other side, rising expectations that their lawyers take mediation seriously and prepare thoroughly, and rising expectations of the mediator. Many of these issues and characteristics surfaced in the Saskatchewan evaluation.

The nature of the program's original goals, coupled with the depth of experience and expertise generated before and through the program's operation, presented researchers with an opportunity to move beyond quantitative questions over settlement rates and timing to the next level of inquiry about the impact of court-connected mediation. The evaluation shows that over the program's ten year history, some of its ambitious goals for cultural and systemic change are being realized. The process of litigation has been altered in some significant ways, for both lawyers and clients. The evaluation report also reveals barriers that continue to affect the experience of lawyers, clients and mediators in negative ways. The Department of Justice has incorporated several changes in response to the evaluation and is poised to move forward in relation to others. In the following discussion, we will provide an overview of the evaluation and will identify some significant results tied to the perspectives of lawyers and clients. As one of Canada's first court-connected mediation programs to enter a stage of maturation, the Saskatchewan program offers a rich learning opportunity in the evolving process of civil reform.

\section{Eval.uating the Saskatchinan Program}

\section{A. Program Structure}

Mediation programs in the civil court structure are rarely complex. Most variations turn on the "mandatory/voluntary" question: to what extent the parties must opt in or can opt out of the mediation requirement. In Saskatchewan, all civil cases filed in the Queen's Bench must proceed to a mediation unless an exemption is formally granted (the so-called "opt out" model also used in Ontario). ${ }^{12}$ Programs also vary somewhat in the procedural requirements that accompany the mediation session. Ontario's program, for example, requires that the

$1 \quad$ See e.g. John Lande, "How Will Lawyering and Mediation Practices Transform Each Other?" (1997) 24 Fla. St. U.L. Rev. 839; Nancy A. Welsh. "The Thinning Vision of Self-Determination in CourtConnected Mediation: The Inevitable Price of Institutionalisation?" (2001) 6 llarv. Negot. L. Rev. I: B. MeAdoo \& $A$. Hinshaw, Jitorney Perspectives on the Effect of Rute 17 on Civil Litigatron in Missouri (University of Missouri-Columbia School of Law, May 2002); Julie Macfarlane, "Culture Change? A Tale of Two Cities and Mandatory Court-Connected Mediation" [2002] J. Disp. Resol. 241 [Macfarlane, "Culture Change?"].

12 The exemption provision, originally set out in The Que'n's Bench Act. 1998. S.S. 1998, c. Q-1.01. s. 42, was superficially amended: The Queen's Bench Amendmem Act. 2004. S.S. 2004. c. 25. s. 2. 
parties exchange a statement of issues in advance of the mediation. In this respect, the Saskatchewan program is not prescriptive. Aside from the requirement to attend the mediation session, the program operates within a minimal framework of procedural rules, something seen as increasingly important in maintaining the program's flexibility.

Another notable variable between programs is how the costs of mediation are covered. The Ontario program provides a roster of "approved" mediators with whom the parties privately contract at a fixed tariff. ${ }^{13}$ In Saskatchewan, mediators are assigned by the Department of Justice from a pool of staff and contract mediators - all experienced mediators with a variety of professional backgrounds, only some of whom are lawyers. Because the pool of Justice mediators is small, mediators work together on a regular basis and have a cohesive commitment to an interest-based approach. ${ }^{14}$ For the initial session, the cost of the mediation is borne by the Department of Justice, with the parties only covering the cost of an increased filing fee. ${ }^{15}$ The cost of any subsequent sessions is shared by the parties themselves.

First introduced in 1994 in the form of a pilot project in Regina and Swift Current, Saskatchewan's mandatory mediation program has since been expanded to Saskatoon and Prince Albert and applies to 80 percent of all (non-family) civil cases in the Court of Queen's Bench. ${ }^{16}$ As soon as a case enters the system, the parties must attend a mediation session; the requirement to attend is invoked "after the close of pleadings" and is subject to few exceptions. ${ }^{17}$ The requirement to attend applies to litigants themselves, although in most cases they will be accompanied by counsel.

The mediation session begins with two individual caucuses, each roughly one half-hour in length, and, in the vast majority of cases, proceeds to a joint session immediately following the caucuses. This first session may last up to three hours in total, leaving parties the option to continue at that time, or later, by agreement with the mediator.

As is the case with standard steps in the litigation process, the program operates with enforcement mechanisms. The mediator will file a Certificate of Completion at the end of the mediation. ${ }^{18} \mathrm{~A}$ party may request a Certificate of Non-Attendance if another party fails to attend. ${ }^{19}$ The mediation session must be completed "before taking any further step in the

By the L.ocal Mediation Commiltec following the submission of a written application.

Based on mediator interviews from Learning from Experience, supra note 8.

Filing lees for statements of claim and defense were increased at the time that the program was implemented, to offset the costs; those fees were recently increased again, in judicial centers where the mediation program operates, from $\$ 130$ to $\$ 200$ for a statement of claim, and from $\$ 60$ to $\$ 100$ for a statement of defense: The Queen 's Bench Amendment Regulations, 2004, S. Reg. 61/2004, c. Q-1.01. Part II. Table 1.

16. The Queen's Bench Act. 1998, supra note 12, s. 42; supra note 10

17 The Queen's Bench Act, 1998, ibid., s. 42(1). The parties ase not generally allowed to participate by conference call, although a written request may be made to exempt a party from altendance. Out-of: province partics are eligible for an exemption, but otherwisc, the provision has heen narrowly construed: The Queen's Bench Regulations, R.R.S. 1999, c. Q-1.01, Reg. I, O.C. 433/99, s. 7: The Queen 's Bench Act, 1998, ibid, s. 42(1).

1* The Queen's Bench Act, 1998, ibid., s. 42(4).

1\% Jbid.. S. $42(3)$. 
action or matter"20 and is avoided at the peril of the non-complying party. In response to the Certificate of Non-Attendance, the court may either order the party to attend mediation, order another mediation with specific terms or, under certain conditions, strike the pleadings of the party that failed to attend. ${ }^{21}$

When the program was first introduced, the initial session was described as "mediation orientation." Mediators concentrated on informing the parties and their counsel about the option to mediate and helping them explore its feasibility in their particular case. ${ }^{22}$ After a short time in operation (and perhaps once a critical mass of lawyers had heard the presentations), the sessions evolved into full mediations. ${ }^{23}$ Mediators began more quickly to wade into the cases themselves, at first with the quiet and sometimes reluctant cooperation of clients and lawyers. Such "working sessions" are now the norm. Unlike some U.S. jurisdictions, ${ }^{24}$ the legislation does not require that the parties negotiate or participate in the sessions in good faith. While concern over good faith participation lingers (see the discussion below), lawyers, mediators and clients have for the most part been motivated by the desire to use their time effectively, to move the case forward, exploring settlement wherever possible - a motivation that demonstrates the increasing acceptance of early mediation in Saskatchewan.

\section{B. Historical. CONTEXT}

While the structure of the program outlined above appears deceptively uncomplicated, it disguises a complex interplay of tension and opportunity. Ten years ago the concept of mandating a process whose success had, until that point, been attributed to its voluntary nature, was both ambitious and controversial. The history of mandatory mediation in Saskatchewan in fact begins years earlier, as a response to the agricultural crisis in the mid1980 s. $^{25}$ Administrators and policy makers hoped to mitigate the impact of the farm crisis by inserting mandatory mediation into foreclosure litigation, requiring lenders to attend mediation with landowners before proceeding with a foreclosure action. The program was a creative solution that increased the potential for lenders to receive money while farmers

Ibid., s. 42(1); note that the interpretation of this clause has been the subject of some disagreement as the program has matured. Sce Learning from Experience, supra nole 8 at 54

$\therefore \quad$ The Queen's Bench ict. 1998, ibid., s. $42(5)$.

: The program was described upon its introduction as mandating "orientation." and not mandating mediation itself: Government of Saskatchewan. Press Release. "Mediation Pilot Projects Under Way" (December 1994); Government of Saskatchewan. Press Release. "Use of Mediation to be Increased in Civil and Family Law Dispules" (March 1994). Even the early Strategic Plan relers to the implementation of "mandatory medialion sessions for mediation orientation in civil cases": Department of Justice. Saskarcherran Justice Sirategic Plan (1993) at I4 [unpublished].

" Two years into the pilot project. lingering confusion over these operational goals is captured in an carly evaluation; Prairic Research Assuciales lic., Initial Mfediution Session Evaluation Report (March 1996) at 18 [unpublished].

24 According to Professor John Lande, at least 22 U.S. states have enacted some type of statutory requirement of good faith. Sec John I.ande, "Using Dispule System Design Methods to Promote (iondFaith Participation in Court-Connecled Mediation Programs" (2002) 50 UCI.A I.. Rev. 69 at 78.

24

The Saskatche wan Farm Security Act, S.S. 1988-89. c. S-17.1, s. 15. It is perhaps not surprising llial the connection between mediation and litigation in Saskatchewan - an agricultural province - had its roots in conflict over land. Saskatchewan's model of mandatory mediation is arguably a part of this province's unique heritage. 
retained their land.$^{26}$ Where farmers could not keep their land, the process allowed them to negotiate the transition in a way that was more humane and respectful, and to emerge with their dignity intact. The farm debt program was an important part of the evolution of a mediation culture in Saskatchewan, which also included a family mediation program and a successful pre-trial settlement program. ${ }^{27}$

The farm program has been considered extremely successful, achieving settlement rates in the range of 70-80 percent. ${ }^{28}$ The volume of mediations generated by the farm program also enabled the Mediation Services branch (now the Dispute Resolution Office) of Saskatchewan Justice to develop a depth of expertise in mediation and a rapport with lawyers and with individual and institutional clients. ${ }^{29}$ Meanwhile, the Branch was gaining experience with mediations in other areas, many of those also involving issues around land use (for example, expropriations and surface rights disputes). ${ }^{30}$ In fee-for-service matters, where the parties voluntarily contract into mediations with a Justice mediator, the Branch was achieving a significant rate of full or partial resolutions - over 50 percent. ${ }^{31}$

The Branch's cumulative experience, along with other examples of successful settlementoriented processes in the province, led them to envision change on a larger scale. The "made in Saskatchewan" approach is clear in the following statement by the then Assistant Deputy Minister in the Department of Justice:

Saskatchewan intends to remain on the leading edge of innovation in the area of dispute resolution, as it has traditionally been in the areas of health care, public insurance and public administration. ${ }^{32}$

The Department's growing experience with mediation was accompanied by shifts in the outside climate. Initiatives were beginning in the federal public service, recognizing the importance of government leadership in promoting collaborative approaches. ${ }^{33}$ Other external factors also played their part. The unregulated state of the mediation profession was starting to cause some discomfort for practitioners and for the govemment, and a program based on a qualified, supervised group of government mediators was one way to deal with these

Ibid.

27 The provision of mediation services (on a voluntary basis) as part of the Unilied Family Court, which operated in Saskatoon from the mid-1970s to the mid-1980s; and the success of the mandatory pre-trial conference system instituted by the judiciary in the Court of Queen's Bench in 1986, achieving settlement rates as high as 66 percent; Ron Hewitt, "Saskatchewan ADR ignored" National (Canadian Bar Association) 6:6 (October 1997) 5. Mediation Services, Monthly Statistical Reports (March 1994) [unpublished].

Over the first five years of the program, almost 3000 farmland foreclosure actions were mediated; ibid. Mediation Services, Department of Justice, Mediation Services: Program Summary [unpublished and undated].

Monthly Statistical Reports, supra note 28.

Hewith, supra note 27 at S; similarly, The Regina Leader-Post described the mediation program as potentially "another successful social policy experimeni" in cur province ("Mediation could prove to be a valuable legal option," Editorial, The Regina Leader-Posı (23 March 1994) A7).

J. Stanford, "Canadian Centre moves to "change the cullure' of public service" Consensus (July 1993) (Publication by MIT- Harvard Public Disputes Program). 
legitimate quality control questions. ${ }^{34}$ Ontario was proceeding with its own court-connected dispute resolution program at roughly the same time." Public opinion, as revealed through the press, and the perspective of some practicing lawyers, reveals a shifting consciousness, a readiness to accept the shortcomings of litigation and consider alternatives. ${ }^{36}$

All of these factors combined to help crack open the window for the Justice Department to proceed with its ambitious goals.

\section{Evaluation Methodology}

Traditional evaluation methods, with their focus on efficiencies and quantitative criteria, fail to account for the rich historical backdrop behind the Saskatchewan program. Qualitative methods, such as focus groups and interviews, are viewed as particularly appropriate where research focuses on the unique internal dynamics of a program, and seeks to differentiate the views and attitudes of different user groups. ${ }^{37}$ These methods can focus intensely on the detail of cases, explored from a variety of perspectives, allowing the researcher to identify and establish significant patterns. ${ }^{38}$ Information so gathered through focus groups and interviews, enriched by some quantitative data, forms the foundation of the Saskatchewan evaluation.

Our purpose was to discover as much as possible about peoples' individual experiences with the mandatory mediation program - lawyers, clients, judges and mediators, as well as the program administrators. Our first step was to conduct an initial round of focus groups with lawyers and clients, and interviews with mediators, at the two major centres offering mandatory mediation (Saskatoon and Regina), in May 2002. These initial focus group discussions were informed by themes identified in earlier research on mandatory mediation programs elsewhere in Canada and the United States (for example, factors in client satisfaction, differing lawyer orientations towards mediation) and what we are beginning to understand about the indices of systemic change in dispute resolution systems (see the

1 Some of the Department's literature does identify that as an issue. $A$ document generated by Mediation Services in June 1994 reveals a consumer-oriented, quality control kind of philosophy, speaking to the responsibility of government to address some of these basic concerns in the delivery of services at a time when the profession is still quite immature: Mediation Services. Department of Justice. The Role of Justice in Mediation Services (June 1994) [unpublished].

1s Sec "Practice Direction: Toronto Region: Alternative Dispute Resolution Pilot Project" (1994), 16 O.R. (3d) 481 and (1995), 24 O.R. (3d) 161.

3. An article in the Globe and Mail relates one of the big success storics, and describes the trend in some large law firms towards the establishment of "dispute settlement groups"; Gailel Baroudi "Moving the corporate battles from courthouse to boardroom" The Globe and Mail (21 June 1994) B22.

3 Within the qualitative research discipline, focus groups are considered to be one of the best vehicles where the researcher's concern is for the collective social experience. Focus groups have been described as the most appropriate method "for exploring people's knowiedge and experiences and ... to examine not only what people think but how they think and why they thisk that way" (Jenny Kitzinger. "Qualitative Researclt: Introducing locus Groups" (1995) 311 (7000) Brit. Med. J. 299 at 300). Focus groups are also described as allowing sensitivity to cultural variables: "fncus groups are more suitable for examining how knowledge, and more importantly, ideas, develop and operate within a given cultural context" (ibid. at 312). For another classic text on focus group methodology see Richard $\Lambda$. Krueger, Focus Groups: A Pracical Guide for Applied Research (New Park, Cal.: Sage Publications, 1988).

iw See, for example, the discussion in A. Michael Huberman \& Matthew B. Miles, "Data Management and Analysis Methods" in Norman K. Denzin \& Yvonne S. Lincoln, eds., Handbook of Qualisative Research (Thousand Oaks: Sage Publications, 1994) 428. 
discussion above). However, these initial focus groups were still viewed as exploratory as an opportunity to discover the particular issues and concerns embedded in the "Saskatchewan experience" - and the interview guide employed open-ended questions and encouraged all comments and reactions (see Appendix A).

Although these initial focus groups included only a small number of lawyers and clients, they produced some clear patterns in response. Client users were very positive about the potential of mediation and generally welcomed the initiative, but were often critical of the role played by lawyers generally in the process, and sometimes of the way the process was handled by their own lawyer. Some clients also expressed concern about what they saw as lack of follow-through after mediation, by either the mediator or their counsel, especially where they believed that an agreement or the basis of an agreement had been reached in mediation, but was never executed or implemented.

Most of the lawyers who participated in the early focus groups were positive about the program, although a number expressed reservations related to the history of the introduction of the program, and several program design issues. The latter included the timing of mediation in the litigation process; the role played by the mediator in mediation; the role played by (other) counsel in mediation, including preparation, information exchange and bargaining in "good faith"; the mandatory nature of mediation for all Queen's Bench cases; and the exemption system.

Our second step was to refocus the questions we were asking of lawyers, clients and mediators, to reflect the issues that had emerged with consistency from the early focus groups. In September 2002, we returned to conduct a further round of lawyer and client focus groups, this time including Prince Albert and North Battleford. ${ }^{39}$ A conscientious effort was made to ensure that lawyer and client focus groups were as diverse as possible, including lawyers from all areas of civil litigation practice, representing both individuals and corporations, and both institutional and personal litigants. This time we met with a total of 31 clients and 62 lawyers.

The September focus group questions are included in Appendix B. These are more closely structured than the May group questions and as a consequence, the data we collected was more specific to program design issues. However, these focus groups still provided ample opportunity for participants to raise other issues and take the discussion in whatever direction they felt was important. In addition, we completed our interviews with mediators, making a total of 13 mediator interviews. The mediator interview questions are included in Appendix D.

The third and final step in data collection was to identify individuals who had not participated in a focus group but whose views, either personally or as representative of a particular constituency, appeared important to the overall credibility and completeness of the evaluation. We conducted a further eight interviews with lawyers and institutional clients (sce and processes with lawyers and clients residing in centres with formal mediation programs. 
questions in Appendix E), and, finally, interviewed a small sample of judges with experience and interest in mediation and settlement processes (see questions in Appendix C).

Contemporaneous notes were taken of all focus groups and interviews. Each meeting was audiotaped to enable checks to be made between the written record and the recording. All electronic records of interviews and focus groups were entered into a data analysis program (NUD*IST ${ }^{* 0}$ ), which enables the coding of data to identify themes and patterns. Codes or categories of issues emerge from an initial analysis of the data, as particular themes and patterns recur. "Thus the codes that are ultimately used to organize and structure the data arise from the data itself and are not preset or externally imposed. Codes or categories are developed through a gradual process and settle into a fixed set that appear to take into account all of the issues raised by the data (see Appendix $F$ for a complete list of codes).

Despite its focus on qualitative data, the evaluation also included an analysis of information obtained through traditional quantitative means - statistics gathered through the court files and files internal to the Dispute Resolution Office of Saskatchewan Justice. This data was used to provide information in the Learning from Experience Report regarding settlement rates, time taken to reach a resolution, links between outcome and type of case and numbers of exemptions. ${ }^{42}$ However, the Report's most significant conclusions are still tied to the information gathered through focus groups and interviews, and the contrasts and commonalities among the views of lawyers and clients in particular.

4) NUD'IST stands for Non-numerical. Unstructured, Data: Indexing, Searching and Theorising: $K$. Buston, "NUD*IST in Action: Its Use and Its Usefulness in a Study ofChronic Illness in Young People" (1997) 2:3 Sociological Research Online at 3. online: Sociological Restarch Online <www.socresonline. org.uk/2/3/6.html>.

N NUD*IST is explicitly based on the grounded theory method of data analysis; $A$. Coffey, $B$. Holbrook \& P. Atkinson, "Qualitative Data Analysis: Technologies and Representations" (1996) 1:1 Sociological Research Online, online: Sociological Research Online <www:socresonline.org.uk/socresonline/1/1/4. html>. For a description of the grounded theory method, see Bob Dick. "Grounded Theory: A Thumbnail Sketch," online: Action Research Resources <uww.scu.eduau/schools/gcm/ar/arp/ grounded.html> and Karen Henwood \& Nick Pidgeon. "Using Grounded Theory in Psychological Research" in Nicky Hayes ef al., cds., Doing Qualitative Analysis in Psy chology (llove, East Sussex: Psychology Press, 1997) 245. For a discussion of the strengths and weaknesses of programs such as NUD*1ST, see Roben G. Burgess, ed., Studies in Qualitative Mlethodology: Computing and Quulitalive Research, vol. 5 (Greenwich, Conn.: JAl Press. 1995).

4: For a full discussion of quantitative data, sec Learning from Experience, supra note 8 at 31-52. Some results are as follows. Records maintained by mediators showed that 13-16 percent of cases settled inside the mediation session, and another 13-19 percent were rated as "agreement likely"; ibid. at 32. An audit conducted during the study shows that while the "agreement reached" category records were fairly reliable, the "agreement likely" labels were accurate only half of the time, pointing to the need for modification in the way that information is gathered internally. and the need for future rescarch; ibid. at 37-40. Count records confirmed that, overall, a high number of cases that had been mediated showed "no further activity" on the file within six to eighteen months following the mediation session. suggesting resolution: but it was concluded that the lack of firm data means it is dangerous to read to much into this suggestion; ibid. at 37. No reliable links could be made between outcome and type of case. except for the "moderately suggestive" pattern that cases of breach of contract were scitling in higher proportions than cases of wrongful dismissal or personal injury, ibud. at 46, and the suggestion that simplified rules cases (involving claims under \$50,000) are settling at higher rates: ibid. at 47 . Thanks to Melissa Wallace for her invaluable assistance in obtaining this data for the purposes of analysis. 


\section{FeEdBaCK From LAWYERS}

\section{A. Changing Views: Acceptance of Mediation}

Ten years into the program's operation, lawyers are expressing surprisingly consistent opinions about mandatory civil mediation. Although many identified reservations about design issues (and a few focused on the absence of widespread consultation at the time that legislation was passed), most lawyers share a positive view of the program. Furthermore, they see its objectives - the faster and more satisfactory reaching of settlement in some civil matters - as fully achievable.

The benefits of mediation as described by Saskatchewan lawyers are highly consistent with the results of work conducted elsewhere. ${ }^{43}$ Many lawyers we questioned spoke about the value of a structured face-to-face meeting that provides an opportunity to meet the other side and evaluate their credibility, as well the credibility of one's own client. ${ }^{44}$ Some counsel also talked about the usefulness of mediation to address and defuse intense emotional issues. ${ }^{45} \mathrm{~A}$ number acknowledged the difficulty of predicting whether a mediation meeting would be useful, a difficulty that could lead to both positive and negative results. Even in circumstances that did not seem conducive to mediation, lawyers have been surprised with what could be gained through early intervention.

Most lawyers, including those who were more negative about mediation, acknowledged a significant shift in the attitude of the Saskatchewan Bar towards mediation in the last ten years. In addition to identifying a cultural change within the Bar in the degree of openness and receptivity towards mediation and mandatory mediation (one respondent describing himself as originally "dragged into this kicking and screaming"), a number of lawyers gave us personal accounts of what was sometimes described as their "conversion." These lawyers all described their initial reactions to the introduction of mandatory mediation as highly skeptical and/or critical, and spoke of becoming gradually convinced of its real worth in at least a significant number of cases. Even those who were more personally cautious broadly supportive but not entirely convinced - described a significant shift of attitudes among members of the Bar. As one lawyer put it, "mediation is no longer a dirty word."

Most respondents were more interested in discussing how the program could be enhanced, not whether it should be maintained. The consensus that emerged from the evaluation was that the program is reaching its goals in many individual cases, but not in others. The reasons given for the failure or inappropriateness of mediation in these cases often refer to the behaviour of other lawyers; for example, the failure of the other side to adequately prepare, to take the mediation process seriously and a general absence of "good faith." These issues,

For similar findings, see e.g. Bobbi McAdoo's study of the Minnesota Bar's response to courtconnected mediation (Bobbi McAdoo, "A Report to the Minnesota Supreme Court: The Impact of Rule 114 on Civil Litigation Practice in Minnesota" (2002) 25 Hamline L. Rev. 401) and Roselle Wissler's study of litigant assessments of the mediation process in Ohio (Wissler, supra note 9 at 650-51). Also, to gather new and important information quickly and informally and as a consequence to be able to assess the risk of proceeding with litigation more realistically. 
and the design modifications proceeding from the evaluation, are discussed further below. In addition, the need to broaden the mediator's role in some cases - and in particular a desire to see greater pro-activity on the part of the mediator - was articulated by a number of lawyers and clients. This conclusion could have significant and general implications for the training of mediators in mandatory mediation programs, and is discussed in a separate section below.

\section{B. Bfing Prepared: Pre-Mtdintion Information Exchange.}

Since mediation in Saskatchewan, like Ontario, generally takes place prior to discovery, what information is exchanged before mediation has a significant impact on the usefulness of a mediation session at this stage. The present Saskatchewan program does not impose any explicit requirements of documentary or other exchange between the parties before coming to mediation. One of the principal reservations expressed about the program by lawyers and clients alike is the lack of information upon which to base substantive negotiations. This informational gap may arise from the nature of the file. In some medical malpractice cases, for example, damages may be difficult to assess at an early stage. However in other cases, adequate information exists, but is simply not made available to the other side in a manner that facilitates settlement discussions.

This problem is characteristic of frequently voiced concerns about a small minority of lawyers, who attend mediation but resist any serious negotiations. Lawyers often framed concerns in terms of an absence of "good faith" - that some of their colleagues were entering the mediation process unwilling to disclose relevant information or to search genuinely for a solution. A number of lawyers indicated, with high levels of frustration, that they have prepared conscientiously for mediation with their client only to be confronted by a lawyer on the other side who was not willing to bargain openly or in good faith. In other jurisdictions using mandatory mediation, some counsel have developed a practice of exchanging affidavits of documents before mediation and ensuring that information is furnished to the other side on their request. ${ }^{\text {to }}$ Some Saskatchewan counsel, especially in smaller centers, told us that they have routinely asked the other side for documents in advance of mediation - a piecemeal solution to a widespread problem.

Other jurisdictions have tried various strategies to address a similar issue of lack of preparedness. Some have required the parties to file pre-mediation submissions (for example, Ontario ${ }^{47}$ ), requirements that sometimes raise confidentiality concerns and often result in only minimal compliance ${ }^{48}$ Good faith rules ${ }^{49}$ are highly controversial, and neither option found favour among our Saskatchewan respondents. Despite the level of complaints about the practice of not preparing or not committing to the process, lawyers were extremely reluctant to consider a rule that would penalize this type of behaviour.

For example, in Toronto and Ottawa; see Macfarlane, "Culture Change?," supra note 11 at 262-63. Ontario, Rules of Ciwil Procedure, r. 24.1

Sec supra note 24.

Twenty-two states in the United States have enacted good faith rules in mediation, with appropriatc penalties. See supra note 24. 
The evaluation concluded that a formal requirement to exchange information in advance of mediation would benefit all the users of the Saskatchewan program. The evaluation recommended the introduction of a new rule of civil procedure that would require that before proceeding to mediation, all parties file their statement of documents with the Court (sometimes described as the affidavit of documents). Such a modification would result in a slight adjustment to the stage at which mediation takes place, facilitating a further exchange of information between the parties that would occur naturally as the litigation process proceeds. ${ }^{30}$ In their response to the evaluation, the Department of Justice has determined that rather than impose an obligation to exchange a statement as to documents, the program manager will be given new powers to delay or adjourn mediation (at the request of one party) until this or other relevant information has been exchanged."

Complaints about lack of preparedness may simply mask a deeper problem. Some members of the Bar continue to regard mediation as a necessary hurdle to be jumped through rather than a constructive settlement opportunity. What is interesting about the data collected from the Saskatchewan Bar is the number of times that lawyers expressed themselves to be fully supportive of mediation, but complained that "the other side" was often less committed. This may or may not be the case, but it suggests that it is now normative to express support for mediation and to "blame" the other side (and in particular their lack of preparedness) for any failures. Predictably, few (if any) lawyers identified themselves as "inadequately prepared," and the risk revealed in such responses is that the inadequacies of the other side will be seen as an acceptable "excuse" for not using mediation constructively. However, the discourse may in fact indicate the achievement of maturity in the program, with the emphasis shifting from a debate over the legitimacy of mediation to a debate over who is doing it most effectively.

\section{FEedBACK From Ch.IENTS}

\section{A. Collateral Benefits: The Value of a Face-to-face Meeting}

Clients we interviewed, consistently identified classic benefits of mediation: the process's potential to humanize the dispute, enabling them to see the other party as a person and the process's ability to defuse emotion. Many tied these benefits to the opportunity to sit and discuss matters with the other party, face-to-face:

\footnotetext{
"David," a corporate client involved in a coniract dispute, said that lie was able to gain more information than he would have in any other process, because the discussion was not constrained by the law. Mediation helped the parties reach an agreement, although the resolution was not finalized for two or three months after the session. He assigned importance to being able to speak honestly, without fear of legal repercussions: "It helped me to offload where I couldn't before"; "I felt I had something to say and to contribute to the process."
}

The message communicated by the following client was repeated often in client focus groups and interviews:

"The Queen's Bench Amendment Act. 200t, supra note 12. s. 2(1.3) 
It all started over hurt feelings. But then the lasyers got involved and it escalated. This was the first time we could sit down, face-to-face, and talk about it. That in itself was worth it.

For some, it was the first time that the parties had actually met. A large institutional client in a commercial contract dispute appreciated that "we finally got to put a face to the voice and meet the people we were dealing with." For some clients, this chance to talk face-to-face left them feeling better about the dispute. An individual we questioned, involved in a debt collection with a large organizational plaintiff, described his experience as follows:

[The process] gave me a chance to express my complaints... I fell quite at ease, and was able to express what I wanted to express, and the [other party] was able to express their concerns. We were both listening and talking. It had a good feeling in that respect.

In another matter, a client involved in a dispute with family members reflected that "there was a very good discussion ... we could see both points of view ... it was so good to sit faceto-face and just talk."

Some clients, like David above, described themselves as having a significant role in the process and making a meaningful contribution. A significant number of institutional and individual clients valued the chance to explain their perspective. For example, a representative from a large corporation said that "it's an opportunity for [us] to make our philosophies and policies known." Others described the value of the information they gained from listening to the other side, leading them to change or broaden their perspectives on the dispute. One client, a representative of a large institutional defendant, expressed relief that he was finally able to see what the real issues were and to understand "where the other party was coming from." Importantly, most clients separated collateral benefits from the outcome of the session; many they described having made these types of gains regardless of whether the matter was settled that day.

That is not to say that such positive experiences were universal. One plaintiff, whose complaints included physical and emotional abuse by the defendant, emphasized that telling her story again was both difficult and unproductive. Some clients indicated that they did not see any collateral benefits emerging from the process at all, with the sole result being delay, and held out little hope for the success of mediation in other cases. ${ }^{52}$ Overall, however, clients focused on the advantages of an early meeting with the other parties in an attempt to settle their dispute.

\section{B. The LAWYeR'S ROLE: LAWYers SilAPING TheIR CLIENTS' EXPERIENCES}

That a face-to-face meeting can be valuable, and can generate collateral benefits for clients, is not a surprising conclusion. These kinds of benefits were arguably the very target of program designers in the Saskatchewan case. The more complex - and less openly anticipated - results of the evaluation are those that speak to the lawyer-client relationship and the lawyer's role. A large number of the clients we talked with spoke positively about mediation and its potential, but went on to express disappointment or even frustration with 
the influence of lawyers on the process. Some described the process as having been thwarted by other factors (such as the position taken by the other side or lack of information). However, over half of the clients complained of the actions or omissions of the lawyers, either their own or counsel for the other side. Whether lawyers deserve to carry this degree of responsibility for the process's outcomes is questionable; what is abundantly clear, however, is the extent to which lawyers shape the mediation experience from their clients' point of view:

\footnotetext{
"Robert," a representative of an institutional defendant, recalls his first few experiences with the mandatory mediation program. His early experiences were largely frustrating, which he now attribules to the influenec of the organization's lawyer, who had instructed him not to speak during the sessions. Once the organization changed lawyers, Robert's experience in mandatory mediation opened up. He now goes into sessions expecting to gain an understanding about "what the other side is really thinking," and comfortable that "if it's a legitimate case, I can say sorry." 33
}

"Mary," another representative of a large institutional client, describes lawyers' attitudes as being largely determinative of the effecliveness, and oulcome, of mediation. Mary's organizalion has consciously chosen to work with a lawyer who supports the mediation sessions, and indicates that "we' re as open as the plaintiffs lawyer is going to be ... we're led by how open they are." She has appeared as the representative for the defendant on roughly ten cases of an almost identical nature, and indicates that what has made the difference in result is not the facts of the case, but the altitudes of the lawyers. ${ }^{54}$

Lawyers are most commonly described as bringing an adversarial approach into the mediation room, "shutting down" open information exchange or being reluctant to negotiate. The frustration experienced by some was expressed by one client as follows: "if I could have sat down with the other person, and no lawyer, we would have settled." Some clients described how their lawyers created an atmosphere that was about "winning and losing"; conducting, in effect, an examination for discovery; taking over the session; and sometimes instructing their client to keep quiet and leave the talking to counsel. ${ }^{\text {ss }}$ One frustrated client, who had wanted to use mediation at the very least to narrow the issues in dispute, summarized the dynamic he experienced as follows:

I find the litigators in the room are wary of [using the session] for fear of showing their hand. That becomes a barrier to moving anywhere in the mediation process.

Almost 50 percent of clients told us that they felt ill-prepared for their mediation session. Many went into their mediations not knowing, or confused about, what to expect. Several said that their preparation was limited to a short conversation with their lawyer in the car on the way to the session, meeting their lawyer fifteen minutes in advance of the session or receiving a letter that told them only where to be and when to be there. Very few remembered receiving the literature that has been developed by the Dispute Resolution Office for the preparation of clients.

is In a few cases, it was obvious to the client that the lawyers were not taking the process seriously: telling the client in advance that the session would be a waste of time or that the process is just a formality. 
Not only do clients notice when they are not adequately prepared by their lawyers, but they also have ideas about what adequate preparation might mean. They want more information exchange between the parties, both in advance and during the session. They want to be "supported" but not "shut down" by their lawyers. They want preparation that includes:

The basics of the mediation, what to expect generally from the process; Information about the principles of confidentiality and "without prejudice"; What paperwork to bring to mediation;

Some information about negotiation strategy, the idea of give and take; Guidance on the appropriate division of roles between lawyer and client - what is valuable for clients to say as distinct from lawyers, and some written material on the client's role and how the client can prepare; and

Discussion of the different purposes of mediation; for example, when the goal should be gaining a better understanding of what the issues are rather than striving for settlement.

One might be tempted to conclude from the above summary that clients would prefer to proceed with mediation alone, leaving their lawyers out of the process. The opposite message came through. Clients who described success stories in mediation were also likely to attribute their success in part to the presence of their lawyers. ${ }^{36}$ Lawyers may be more likely to judge the likelihood of success in mediation based on the character of the dispute. For clients, however, the single most influential factor is the approach taken by the lawyers. Despite increasing numbers of applicants, lawyers remain the primary agents of disputing in civil justice processes. ${ }^{57}$ The results of the evaluation are a timely reminder of the significance of their impact on the process.

\section{Feedback about the Mediator's Role: The Call for Pro-activity}

It is interesting to note that the mediators in the Saskatchewan program, unlike mandatory mediation programs elsewhere in North America, are generally non-lawyers. Roughly half of the program mediators are veterans of the farm debt program, and a number are also experienced family mediators. However, there is a broad acceptance of non-lawyer mediators by the Saskatchewan Bar and there are some important lessons for other jurisdictions in the expectations Saskatchewan lawyers have of the mediator's role. While it is common for court-connected mediation programs to adopt a facilitative, non-evaluative approach to resolution, in the Saskatchewan Queens Bench this admonition seems to have greater authenticity than other programs given that fact that few mediators have legal training. ${ }^{58}$ The

36

Several clients spoke, for example, of how important it was that their lawyers provided "support" to them. One client said that he needed his lawyer to keep him calm and locused in the process.

Rising numbers of self-represented litigants are suggested by falling numbers of approved civil legal aid applications. Successful applications dropped from 386.617 to 247.536 , a 36 percent decrease. Sec Canadian Centre for Justice Statistics. Legal Aid in Canada. Resource and Caseload Data Tables 1997-98, Catalogue No. 85F0028XIE (Otawa: Statistics Canada, 1999) at Table 10; Canadian Centre for Justice Statistics, legal Aid in Canada. Resonrce and Caselocd Statistics 2002-03. Cataloguc No. 85F0015XIE (Ottawa: Statistics Canada, 2004) at Table 12.

There is some evidence to support the assertion that despite a formal emphasis on a facilitative approach, significant amounts of evaluation take place in mandatory mediation. See Nancy A. Welsh, "Making Deals in Court-Connected Mediation: What's Justice Got to Do with it?" (2001) 79 Wash. 
present cadre of Justice mediators are very cohesive in their commitment not to give any opinion on the legal merits of the case. As one mediator expressed this to us, "I see my role in these files as being to facilitate, to assist people in their communications, to poke, prod, give gentle nudges, to try to move people forward."

Lawyers who participated in the study fully appreciated that most mediators were not qualified to provide a legal assessment, and few viewed this as a problem or a disadvantage. Most lawyers appear to accept mediation as a purely facilitative process, thus clearly distinguishing it from the later pre-trial conference process. A number of lawyers commented that given the timing and nature of pre-trials in the Queen's Bench, it made more sense to make mediation a distinctive and earlier process. There was no suggestion that the mediator should act as a judge; in fact, there were many examples in the interviews we conducted of lawyers distinguishing the role of a judge from the role of a mediator. The judicial function was seen as quite different from that of a mediator. For example:

Some clients won't settle unless a judge tells them that they're liable.

The pre-trial judge provides evaluation - it is sometimes imporlant for the client to hear what judge says about their case.

Members of the judiciary who were interviewed also stressed the need to offer two distinctive processes to encourage settlement - one a facilitative mediation, and the second, a more evaluative process as the action proceeds closer to trial.

Compared with jurisdictions where mediators are almost always lawyers, ${ }^{59}$ Saskatchewan presents a striking example of a culture that has become attuned to the benefits of an early, purely facilitative mediation model There appeared to be relatively little objection to this approach among participants in the evaluation. Indeed, many lawyers and their clients expressed their appreciation of the skill and experience of the Queen's Bench program mediators. This stands in sharp contrast to lawyers elsewhere, who are sometimes completely dismissive of non-lawyer mediators. ${ }^{60}$

The preference for a facilitative approach was not unanimous among the lawyers interviewed. Some lawyers would prefer a more evaluative approach in mediation generally, and others could see some types of cases in which an evaluation would be more useful than a purely facilitative approach. While these comments came from a small minority, taken with

\section{U.L.Q. 787 at $805-806$}

For example in Florida, the rules require mediators in the circuit court to be members in good standing of the Florida Bar for the past five years ("Florida Rules for Certified and Court-Appointed Mediators," r. 10.00 General Qualification (last revised 2000)). In Ontario it is not necessary to be a member of the Bar to be appointed as a mediator although the rule require a familiarity with civil procedure. See "Local Mediation Committee Guidelines for Selecting Mediators - Ontario Mandatory Mediation Program," online: Ontario Mandatory Mediation Program < www.attorneygeneral.jus.gov.on.ca/english/ courts/manmed/guidel ines.asp $>$. There seems to be anecdotal (but not officially recorded) evidence that lawyers are greatly preferred as mediators over non-mediators, especially in Toronto. See Macfarlane, "Culture Change?," supra note 11 at 285. 
other suggestions about mediator role, they suggest that more might be done to provide counsel with choices over mediators (style, expertise, etc.). In our final recommendations for the Saskatchewan program, we proposed that lawyers be provided with a choice among the available cadre of mediators, in order to fit the mediator to the particular case. Although program managers have not implemented a formal selection system, they continue to accommodate lawyers' preferences on an informal basis.

The other striking response, offered consistently by both lawyers and clients, reflects a desire for a more interventionist style (while stopping short of cvaluation) on the part of the mediator. A significant number of remarks from both lawyers and clients suggest that program users want the mediators to take a more proactive role in working for settlement in the session. Where settlement is not an option, many lawyers and clients indicated an interest in having mediators help to "manage" the file, for example, by assisting to set a future timetable for steps in negotiation or litigation, instead of simply releasing the parties at the end of the session.

Among lawyers in particular, the call for pro-activity tended to be linked to the complaint that the "other side" was not taking the mediation seriously. Lawyers spoke often of the need for mediators to "lean on" the parties and their lawyers more, to "get their hands dirty" and "make us talk." Other consistent comments included the need for mediators to stand up to counsel who are unwilling either to stay in the session or to bargain in good faith; hold counsel to account where they are unwilling to exchange information in the session (and have not done it in advance); prevent counsel from dictating the tone of the meeting; require counsel to answer questions and to justify their positions; and generally work harder to keep the parties at the table. These comments clearly point to a desire for a mediation that keeps the parties focused and working on settlement, even where there is initial resistance. Many lawyers preferred a strong-armed approach (where needed), and still saw it as distinct from an evaluative function. These respondents believed that a facilitative mediator will be most effective where she is proactive and, sometimes, quite directive.

For the most part, clients were very complimentary about mediators. ${ }^{61}$ Most described an atmosphere that felt comfortable and attributed that to the work of the mediator. At no point were concerns about mediator neutrality raised. Where there were complaints, they were consistent with those offered by lawyers: that the mediator was too hands-off, not "active" enough or did not "take control." The most common view was that it is the mediator's responsibility to "push back" against the lawyers and to exercise their persuasive powers to keep the negotiation moving forward. The clients' desire for mediators to be more proactive in this way is clearly linked to their frustration with the lawyers. ${ }^{62}$

Just as frequently, the clients we talked with expressed a desire to have mediators be more proactive following the mediation sessions:

6. Only two of the clients who called for more mediator pro-activity had not also identified frustration with the lawyers. 
"Kerry," a personal injury client, felt posilive about mediation, and about the fact that she did much of the talking in the session. However, she would have liked more to happen in the period of time following the session: "So I got to tell my story, so what? I've told my story a million times." It was important for her to see progress after the session, and this did not happen."

Clients are not as accustomed as their lawyers to the sometimes slow pace of the litigation process. Many that we talked to were frustrated in that they seemed to make some progress in the mediation session, but that things fell apart after the session, or sat dormant for a period of time. Many saw it as the mediator's role to continue to facilitate the file's progress after the initial session, issuing a clear invitation for mediators to do more follow-up work.

These comments suggest an important, although perhaps slight, shift in the conception of the mediator's role in mandatory court-connected programs. There has been a tendency at least in mediation training - to conflate a facilitative approach with a hands-off, nondirective style of mediation. Equally widespread is the assumption that evaluative approaches to mediation are characterized by some pressure and arm-twisting by the mediator. This evaluation shows a program moving beyond stereotyped assumptions and acknowledging that some combination of characteristics is required. Its responses affirm that the ultimate focus (facilitating an open discussion) can be achieved through a variety of styles (from hands-off to hands-on) - a mediator can use an interest-based approach, keeping the parties centered on achieving a better understanding of each other's concerns and goals (rather than making assessments of the strength of each position), and do so in a way that employs directive techniques - reality-lesting, confronting, caucusing and otherwise re-framing or influencing the direction of the discussion and the parties' commitment to the process.

Another layer of complexity in images of the mediator's role also emerged from the study. The comments of lawyers and clients, described above, indicate that a need for pro-activity might arise at different stages in the mediation. The mediator may be called to use her persuasive powers to influence how the parties and their counsel are interacting with each other - to influence the development of the negotiating relationship among them. This might involve, for example, encouraging the parties and counsel to negotiate openly and in good faith, wherever possible - an opportunity that generally arises in the heart of the session. On the other hand (and usually at the inception or closure of the mediation), the mediator may be called to be proactive in an administrative capacity: designing and managing the procedural elements of mediation to maximize the process's potential. Perhaps due to the absence of formal procedural rules surrounding the sessions, clients and lawyers often expect some process management from the mediator, including arranging for the exchange of information in advance; ensuring that parties with decision-making power and the proper authority attend; scheduling a second session where appropriate; ensuring that undertakings made during a session are completed; and taking responsibility for any other necessary follow-up work after the initial session has wrapped up. Both dimensions of mediator pro-activity - the development of a good negotiating relationship and a type of managerial leadership role - are linked: each supports and sustains the other. 
These comments have important implications for the training of mediators not only in Saskatchewan but also elsewhere. The Dispute Resolution Office has picked up on both forms of pro-activity in its post-evaluation changes. Mediators are being encouraged to be stronger about keeping people in the room and working towards settlement. They are also being encouraged to do more front-end work, for example, contacting lawyers ahead of time to discuss the file and prepare for the session. ${ }^{\text {b4 }}$

\section{Characteristics of a Maturing Program}

Refining and strengthening the Saskatchewan program's commitment to participatory justice - whether in the degree of pro-activity of its mediators or the level of genuine engagement by participating counsel - is a matter for training and long-term future debate and development. Areas of procedural weakness identified in the evaluation report have already been addressed in amendments to the legislation, passed in June $2004 .^{65}$ In making adjustments to the program, program managers have seized on two key conclusions in the Learning from Experience Report: ${ }^{66}$ that something more needs to be done to encourage information exchange in advance of the mediation session, and that there needs to be more flexibility in process design to respond to procedural needs in individual cases. Amendments to the primary legislation now give the Director flexibility to postpone the mediation session until after the parties have exchanged documents (or documentary lists), or until any other time, and also clarify the court's ability to refer a case to mediation at any time later in the litigation process. They maintain an emphasis on early sessions, but invite rearrangement of the process where it is likely that a more productive mediation will occur at a different stage.

The evaluation revealed the need for program modifications, but not wholesale change. The Saskatchewan program has reached a "settling point" in its evolution, having passed clearly through the early stages, where building legitimacy was the primary concern. Although the program cannot be static (it must continue to be responsive to changing context and to evolve accordingly), it has reached an important point of maturation. It is currently influenced by three forces that, in light of the program's early controversies, are especially significant. We offer these observations as characteristics of a maturing mandatory civil mediation program: the preference for flexibility, an alignment of goals and extending the overall legitimacy of mediation and its place in the local legal culture.

\section{A. A Preference for Fleximitity}

With the layers of procedural rules that surround litigation, it would be tempting to move a court-annexed mediation program in the same direction. In Saskatchewan, however, program managers have decided to do the opposite, minimizing the procedural complexities and requirements of mandatory mediation. The original choice may have been a strategic one, designed to minimize the intrusion of the program from the perspective of lawyers. Striving for simplicity also meant however that the program inevitably took a "one-size-fits-all"

i. Interview of Ken Acton, Director, the Dispute Resolution Office to authors (August 2004)

as The Queen's Bench Amendment $\mathrm{Act}, 2004$. supra note 12.

"This section describes two legislative changes; other program "adjustments" (embodied in regulations or policy change) have been described earlicr in this article. 
approach. As the program matures, in the wake of the evaluation, there has been a renewed commitment to flexibility that will leave room for the professionals involved (mediators, administrators, lawyers and judges) to exercise their judgment on a case-by-case basis.

Until now, one of the program's areas of weakness has been the failure of parties to exchange any information in advance of the session. Instead of inserting a requirement that parties disclose positions or documents before mediation, program managers have committed to encouraging mediators to do more "upfront" work on files (contacting lawyers in particular), and clarified administrators' ability to defer mediation until some later point in the litigation process, where appropriate and justifiable (for example, after examinations for discovery). Additionally, the "certificate of completion" and accompanying "certificate of non-attendance" ${ }^{167}$ has been changed to a "certificate of compliance," which increases flexibility in the determination of who must attend the mediation session. Previously, all litigants had to attend the session, unless exempted by either the Director or the court. This new wording allows the mediator to determine, on a case-by-case basis, who should be attending in order to comply with the program's intent. So, for example, in a case where a number of individuals have been sued in their capacity as representatives of an organization (members of a board, for example) it may be more important to have a representative of the organization than to require that board members attend individually ${ }^{69}$ Both of these changes are minor adjustments and to an extent simply confirm informal practices that already existed. As the program passes through these stages of its development, however, a continued commitment to flexibility is strengthened in these and other ways.

What is significant about a commitment to maintaining and even enhancing flexibility is that it invites - indeed requires - the professional players to invest some trust in each other. Underneath the desire for flexibility is a vision of a mediation program that is offered on a large-scale and is accessible to all, but is still capable of responding to the particular procedural needs of individual cases: identifying who should be at the table and what information is needed in order that the session can be productive, engaging the lawyers and their clients in a meaningful discussion regardless of whether they have yet initiated settlement discussions and shifting to case management when more steps in the litigation process are inevitable. Program managers need to invest some trust in the judgment of lawyers who ask for a mediation session to be deferred; equally, lawyers need to trust mediators and program managers who suggest that discoveries, and post-discovery negotiations, are not always or necessarily the most effective or efficient way to reach settlement in a particular case. Mediators and lawyers need to trust each other as they discuss files in preparation for upcoming sessions.

In the early years, trust was absent and flexibility was not a message that would carry the program forward. Some rigidity in the program structure was required in order to get lawyers and litigants accustomed to the option of mediation. Even now, Saskatchewan lawyers

The Queen's Bench Act, 1998, supra note 12, s. 42(3).

The Queen's Bench Amendment Regulations, 2004, supra note 15, s. 6(2).

The certificate of compliance is not intended to act as a cerlificate of good faith; see previous discussion. The new cernificatc of compliance also fits with the commitment of mediators to be more proactive, requiring that they fully discuss with counsel who needs to attend the session to make it an effective use of time. 
generally agree that the mediation program should not be completely flexible (for example, there was a clear view against substituting an opt in program ${ }^{70}$ ). Over the ten years of the program, with some accompanying cultural and attitudinal shifts, professionals involved are beginning to consider themselves team players more than adversaries.

The program's longstanding commitment to a facilitative and non-legalistic mediation process may have been the ultimate factor in developing trust. Non-lawyer mediators, using an interest-based style for mediation sessions, re-framed the negotiation process, focusing on client concerns and overall objectives rather than arguing and evaluating legal positions or strategizing on litigation process. This was the lawyer's area of expertise and it now appears clear the Saskatchewan mediators neither wished to nor were expected to go there. Facilitative medjators have their sights trained on the potential benefits - uncovering hidden obstacles to a resolution and bringing all parties and their counsel "to the same page" in understanding what it will take to satisfy clients on both sides of the dispute. While mediators may have different techniques at their disposal (see discussion of mediator pro-activity above), the only way to achieve such an open discussion is with willing engagement of the lawyers. The program's commitment to a facilitative mediation process, relatively free of procedural rules, guaranteed this dynamic: that in order for the process to be successful, lawyers and mediators would have to work together, case by case. The program required the development of relationships between lawyers and mediators, and ultimately, the building of trust. What was perhaps the program's greatest challenge - inserting a non-legalistic and quasi-informal step into the litigation process - became a foundation for growth.

At this juncture, now that working relationships among lawyers, mediators and program managers are beginning to settle, the Saskatchewan program can easily sustain adjustments that continue to emphasize the exercise of discretion and flexibility.

\section{B. GOAL AlignMent}

As the program has matured, views on all sides - originally polarized - have begun to merge. Common ground among the various perspectives is easier to locate. Not only have lawyers and clients generally accepted that mediation has a place in the resolution of civil disputes (a conclusion that obviously propelled mediators and program managers), but mediators have begun to define their jobs in a way that matches the multi-dimensional, proactive role envisioned by clients and lawyers, and described above.

Interviews with mediators conducted during the course of the evaluation revealed an emerging complexity (perhaps a dichotomy) in terms of how they conceptualized their roles. One group was more likely to describe the mediator's role as classically hands-off: to help the parties understand each other, to respond to resistance softly, by building rapport, asking questions and using gentle prods. The other group was more likely to describe the mediator's role in a way that invites more force and direction: to get the parties and their lawyers working, believing that keeping them in the room is necessary to reach mediation's educative and transformative function. Each reveals differing levels of comfort with mediator proactivity. The second perspective may be regarded as somewhat inconsistent with a "classic" 
facilitative style, and also with the program's original commitment to a "hands-off' educative environment. Despite this, interviews revealed it to be a view that was as or more predominant as the first among program mediators - suggesting that experienced mediators, along with lawyers and clients, now see a need for strong pro-activity in many cases.

Mediators in this second group tend to worry less about their credibility with lawyers and the legal community, feeling comfortable with the relationship building they had already done. Not surprisingly, their views on the mediator's role were much more closely aligned with the views expressed by both lawyers and clients. Once again, this speaks to the shift that can occur when a program reaches a certain level of maturity, and the process agents (mediators and lawyers alike) gain some history with each other. Time and experience may move the professional players closer together in terms of their expectations of each other and the process.

\section{EXTENDING LegitimaCY}

Like any innovation, and especially those that impact social relationships and benefits, the success of mandatory civil mediation depends to a large extent on its ability to become regarded as legitimate (credible, effective, worthwhile) in the eyes of its users, both lawyers and clients. The Saskatchewan evaluation confirmed what other studies of court-connected mediation have shown - that with increasing exposure to mediation and experience with the process, more positive attitudes emerge among both lawyers and clients and that these same positive attitudes tend to beget better results" - which might include more serious preparations, more effective negotiations with better use of the expertise of both third party and lawyers, and better all round outcomes both substantively and in terms of procedural satisfaction.

Saskatchewan also offered a chance to speculate a little further on some of the phases or stages of legitimacy as they emerge over time as a program matures and experience deepens. We concentrate here in particular on the attitudes towards the legitimacy of mediation among lawyers, as they still appear to play the primary role in determining client attitudes. ${ }^{72} \mathrm{We}$ suggest that it may be helpful to conceptualize deepening legitimacy in three possible phases or stages.

In stage one, as a new mandatory mediation program is introduced, generally, there is widespread skepticism. The introduction of a new procedural step is regarded as implicitly critical of what lawyers and courts have done to this point. Civil justice reform may be politically motivated (perhaps to save money) and this adds to the skepticism. A common attitude among lawyers at this stage is not to take the innovation especially seriously, and sometimes to find ways to assimilate mediation into more familiar and established practices (for example by busing mediation as a positional negotiation absent vital information). This

" See e.g. John Lande, "Getting the Faith: Why Business Lawyers and Executives Believe in Mediation" (2000) 5 Harv. Negot. L. Rev. 137 at 171-76; Lynn Mather, Craig A. McEwen \& Richard J. Maiman, Divorce Lanvyers at Work: Varieties of Professionalism in Practice (New York: Oxford University Press, 2001) at 58; and Macfarlane, "Culture Change?," supra note 11 at 317-18. 
attitude is frequently communicated to clients, who see mediation as a waste of their time and money.

In stage two, which we suggest will emerge once most lawyers and institutional clients have had multiple experiences of mediation (that is, the stage mediation has reached in Saskatchewan), counsel's attitude towards the legitimacy of mediation becomes more complex and tums on some important distinctions. Most lawyers will now feel that they need to explain their position on mediation with more depth than previously, when they could get away with being fairly dismissive. Generally attitudes become much more positive. In Saskatchewan very few of the lawyers with whom we spoke (only 13 percent) did not begin or end their descriptions of their mediation experiences with some acknowledgement of the unique benefits of mediation - indicating the growing legitimacy of mediation and showing clearly a movement away from phase one, above. At this stage it is important for lawyers to associate themselves with some degree of positive attitude towards mediation. ${ }^{3}$

However support for mediation is by no means unequivocal. At least two distinct sets of equivocations are apparent from our Saskatchewan data. Around half of the Saskatchewan lawyers whom we interviewed for this evaluation assert that while they are now personally convinced that mediation is an excellent process, its potential is often diminished by the approach of other lawyers who do not take it seriously - who have not "seen the light" as they have. In blaming "the other guy" for problems with the mediation process these lawyers were far from unambiguously committing to its use — rather they were providing a rationale for why they might not always take it very seriously themselves. They are, however, also recognizing that the answer to some of the problems they identify with mediation may lie within the legal community itself.

A second group (roughly 50 percent) defined the barriers to the realization of full potential for mandatory mediation as wholly external or structural. This group blames faulty system design (for example, lack of adequate screening processes or the timing of mediation), mediators (as we have seen some are characterized as insufficiently proactive) or program managers (sometimes seen as overly bureaucractic and inflexible) for their disappointments with mediation. These lawyers are saying that mediation is a good innovation and that they like it, but it is destined to fail because of reasons that have nothing to do with the role of the Bar.

In stage three, the ambivalence and blaming has been replaced by a widespread desire among lawyers to ensure their expertise in mediation processes, with a range of new skills and knowledge becoming important to their continued professional development. It may be that stage three legitimacy is reached faster in smaller communities where the legal culture (or "community of practice" "74) is more cohesive with stronger prevailing norms and a relatively homogeneous client base. In Saskatchewan, this stage appeared to have been

This sentiment is captured in the words of one Ottawa lawyer speaking about mandatory mediation in that city: "Good lawyers, in this town, understand what mediation's about ...I think that's what is accepted in the system, so lawyers have made the change" (quoted in Macfarlane, "Culture Change?," ibid. at 316). See also the discussion of the impact of the prevailing ideology of one's "community of practice" in Mather, McEwen \& Maiman, supra note 71 at 41.63. 
reached in one such smaller community. Our discussions with Prince Albert lawyers were characterized by a seriousness and commitment to mediation from senior down to junior lawyers, with an emphasis on describing positive enhancements (for example, conventions over advance exchange of documents) rather than complaining about process spoilers, either external or internal.

The extent of mediation legitimacy appears to be directly tied to the consciousness and rationalizations of lawyers. The Saskatchewan program reflects at least a stage two, or in some cases a stage three, level of legitimacy.

As court-connected mandatory mediation continues to play a role in civil justice reform across Canada, we need to find reliable means of evaluating not only the achievement of primary program goals - such as settlement rates and client satisfaction - but also the impact of the local cultural context, historical factors and the nature of any systemic changes including the consciousness of lawyers. The Saskatchewan evaluation provided an opportunity to look deeper into these broader and perhaps more complex factors in "successful" civil justice reform. Mandatory mediation programs in the general civil court structure are only just coming of age, offering new opportunities to define and assess the characteristics of maturing programs. The indices of maturity that are appearing in Saskatchewan are important signposts, with the potential to guide future design and development decisions across the country. 
APPENDIX A:

Focus Groups Round ONE (May 2003)

\section{Lawyers Focus Groups}

The questions we have been asked to try to answer are:

1. to evaluate how far the mediation program in the Queen's Bench meets the needs of the people of Saskatchewan (focusing on discussions with client users);

2. to assess the impact of the mandatory mediation program on civil litigation practice in Saskatchewan (focusing on discussions with members of the Bar).

What brought you to this meeting? What would you like to tell us about your experience of the mediation program?

\section{Supplementary questions}

1. What is your view of the style and knowledge of the mediators?

2. What if any issues do you have with confidentiality of mediation?

3. Should this program be extended to the simplified rules procedures?

4. What are your views on the timing of mediation?

5. Do you think there has been "culture change" around the idea of using mediation?

6. What are the implications for legal education and training?

\section{Clients Focus Groups}

The questions we have been asked to try to answer are:

1. to evaluate how far the mediation program in the Queen's Bench meets the needs of the people of Saskatchewan (focusing on discussions with client users);

2. to assess the impact of the mandatory mediation program on civil litigation practice in Saskatchewan (focusing on discussions with members of the Bar).

What brought you to this meeting? What would you like to tell us about your experience of the mediation program? What was on your mind when you took up the invitation?

APPENDIX B:

Focus Groups Round Two (SEPTEMBER 2003)

\section{Lawyer Focus Groups}

\section{Opening question}

What are your general perceptions of how the program is working - what impact has it had on your litigation files? 
Is mandatory mediation changing the culture of disputing in the courts?

\section{A. Impact}

In what ways has the culture of your local Bar been affected by the introduction of mandatory mediation in your jurisdiction? Have attitudes towards mediation amongst members of the local Bar changed?

Secondary benefits - subsequent activity (oversight by mediators?)

In relation to other procedures:

- Is mediation appropriate for matters proceeding through the simplified rules procedure? Why/why not?

- Does participating in earlier mediation make any difference to cases that do not settle, and continue to pre-trial? (e.g. any less time spent on discoveries?)

\section{B. Process Critique}

What timing would you like for mediation? And why?

Some lawyers have suggested that mediation is not suitable for every case and that they would like different processes for different cases - including but not limited to different timing for ADR. For example, some cases might require more than one session; discoveries to have taken place first; or a neutral evaluation to be provided. On the other hand, the existing system is simple and seems fair because it is applied to all civil cases without exception. What do you think? (optional: offer example of the residential schools cases)

- What is your view of the role taken by the mediators in this program?

Have you ever participated in a mediation which you felt was a complete waste of everybody's time? Why was that? What could have been done differently to make it more productive?

- Why would you want conference calls? Some lawyers have told us that they would like greater flexibility over the substitution of conference calls for face-to-face meetings, perhaps to enable them to get the right people on the line. Others have told us that they support the emphasis on keeping mediation a face-to-face process. Is this an issue for you and what do you think?

- Some lawyers have told us that they are frustrated that sometimes opposing counsel will not provide necessary disclosures prior to mediation and is poorly prepared, perhaps appearing without authority to settle. Is this a problem for you and what if anything do you think could be done about it? (Optional: some jurisdictions tackle 
this problem with a "good faith" provision - there is something like this in the farm mediation program. Do you think that is needed here?)

- What is your view of the mediator(s) you have worked with? Are there sufficient experienced and effective mediators to meet your needs here in ? Selecting your own mediator?

\section{Optional question}

- Some lawyers we have talked to have said they would like the mediators to take a more proactive, case management role where they would set sessions, hold premediation discussions with the lawyers and generally oversee the case through mediation. Is there a need for such a role?

- How well prepared have you felt by your legal and professional education - and what more, if any, training would enable you to be more effective in mediation?

Check back to opening question.

Check first go-round to ensure that all issues have been captured by discussion.

\section{All Things Considered Question}

- Do you think mandatory mediation is a good thing for civil litigation in Saskatchewan? What would you change?

Have we missed anything?

\section{Client Focus Groups}

Introductions

Purpose and format of focus groups

Opening question

We would like to begin with your overall impressions of the mediation program, before getting to the specifics of your experiences.

How far is the mediation program meeting the needs of the people of Saskatchewan?

\section{A. Client satisfaction}

Some of you will have been to only one mediation, others more than one. In either case, what now is your view of mediation? How positive/negative?

What is your view of the mediator(s) you have worked with?

How do you feel about your own role in the mediation process? (Was it a good experience? One that you would have preferred your lawyer handle without you? One that you would like to handle by yourself as far as possible?) 
- What particular challenges do clients encounter in using mediation?

\section{B. Program Structure and Process}

- How well are clients being served by lawyers in the mediation process?

- How satisfied are you with the advance information provided to you by the court and/or your lawyer, and how could this be improved?

- Some clients have told us that they would prefer mediation to be offered even earlier, perhaps before a lawsuit is begun - and others have said that it is pointless to mediate until just before trial. What do you think?

- Are there any other issues which you think are affecting the effectiveness of the mediation program for clients? For example:

- Is it important to select your own choice of mediator?

- $\quad$ To be able to attend mediation without counsel present on either side?

- Should there be some way of monitoring that disclosure has taken place and that lawyers are properly prepared for mediation?

Check back to opening question

Check first go-round to ensure that all issues have been captured by discussion

\section{All Things Considered Question}

Do you think mandatory mediation is a good thing for people who need to bring civil actions in Saskatchewan? What would you change?

Have we missed anything?

\section{APPENDIX C: INTERVIEWS WITH JUDGES}

1. What is your general impression/perspective on the mandatory mediation program?

2. What do you see as the appropriate relationship between mediation and pre-trials (in terms of purpose, objectives, duration, outcomes, skills)?

3. What should be the role of the judge in settlement, from a philosophical perspective? How does this compare with the role of a mediator?

4. What matters should be exempted from mediation?

5. What leadership role might judges play in building the credibility of mediation?

6. What is your opinion about the process whereby judges make referrals into mediation in the present process, and do you have any suggested modifications?

7. Do you have any other comments on the mediation program? 


\section{APPENDIX D: \\ MEDIATORS INTERVIEWS}

1. What do you see as your role in a mediation?

2. What makes a difference to the usefulness of mediation?

3. Do we need a good faith rule here?

4. What is your view on the timing of mediation?

5. Is there any need for case screening? For example, should residential schools cases be included in the program?

6. What do lawyers need to do to make better use of mediation?

7. How do you think the mandatory mediation program should handle Simplified Rules cases?

8. Have you seen a change in the use of mediation over the time you have been working in the program?

9. How do you determine classification of outcomes $(\$ 2 / 3 / 4)$ ?

10. Is there any change in your role that you believe might increase the number of $\#$ I's? (cases fully resolved in the mediation session)

11. What is your role in crafting the agreement?

12. Is there an appropriate follow-up role for the mediator?

13. Do you think that the program's internal systems and resources could or should be improved in any way?

14. Do you have any other general comments about changes, improvements in the mandatory mediation program?

\section{APPENDIX E: \\ FOLLOW-UP INTERVIEW QUESTIONS FOR SFI.ECTED LAWYERS AND INSTITUTIONAL Cl.IENTS}

1. Generally, what has been your experience with the mediation program?

2. What do you think about the timing of mediation in the Queen's Bench program?

3. What effect, if any, have you seen the mediation process have on your future (business or personal) relationships (for example, the likelihood of future litigation)/ the way you might handle a future conflict?

4. Would you be interested in pre-mediation contact with the mediator (review purposes, e.g. to clarify who will be coming with what authority, to facilitate exchange of information, ascertain that all parties coming prepared and in good faith, etc.)?

5. Would you be interested in any post-mediation follow-up by the mediator to ensure that next steps were completed?

6. In your experience, how creative are the agreements reached in mediation? How durable?

7. (For lawyers) Do you see secondary/collateral benefits from mediation? Can you describe these/give examples?

8. Do you think that the present program would benefit from increased judicial oversight? For example, cost consequences for parties who come unprepared? 
9. What types of further training do you think would improve the effectiveness of lawyers in the program?

10. Do you have any other comments or suggestions for program modification?

\section{APPENDIX F: \\ CODES FOR NUD*IST PROGRAM}

Demographics

- centre

- role (lawyer/client/judge)

- gender

General expectations of the mediation program

Evaluative Comments

- positive

- negative

Timing of mediation

- $\quad$ should come later in the process

- should come earlier in the process

- is OK where it is

The mediator's role

- comments regarding evaluative/facilitative style of mediator

- $\quad$ pre-mediation role of mediators

- role of mediators in drafting settlement outcomes

- post-mediation role of mediators

- overall level of intervention by mediator

\section{Compliance}

- positive experiences

- negative experiences

- reasons given for experiences

Collateral benefits of mediation

Culture change among the Bar

Implications for legal education

Suggestions for program modification 
- regarding compliance

- regarding the use of conference calls

- regarding the role played by the mediator

- regarding ensuring "good faith" by all parties

- regarding case management as a feature of the mediation process

- regarding voluntariness and allowing exemptions from mediation

- the relationship between mediation and pre-trial

Cost considerations 